\title{
The Arctic ocean-ice system studied by contamination modelling
}

\author{
Larissa Nazarenko, ${ }^{1,2}$ Tessa Sou, ${ }^{1}$ Michael Eby, ${ }^{3}$ Greg Holloway ${ }^{1}$ \\ ${ }^{1}$ Institute of Ocean Sciences, 9860 West Saanich Road, P.O. Box 6000, Sidney, British Columbia V8L 4B2, Canada \\ ${ }^{2}$ Institute of Northern Ecology Problems, 14 a Fersman Streel, Apatity 184200 , Russia \\ ${ }^{3}$ School of Earth and Ocean Sciences, University of Victoria, P.O. Box 1700, Victoria, British Columbia V8W 3P5, Canada
}

\begin{abstract}
The Arctic represents a relatively pristine frontier that is vulnerable to pollution. Substances originating at mid latitudes are transported to the Arctic by atmospheric processes, ocean currents and rivers. These pollutants can accumulate in the Arctic environment. Testing of nuclear weapons, dumping of waste and operation of ships, and nuclear power plants also pose threats.

To investigate possible pollutant pathways we used a multi-level primitive-cquation ocean model, coupled to a dynamic-thermodynamic sea-ice model. Coupling included conservative transfer of momentum, heat and fresh water. Atmospheric forcing (wind stress, temperature, humidity, radiation and heat fresh-water fluxes) was supplied by datasets or bulk formulae. Open lateral-boundary conditions for the ocean model were supplied either by datasets (temperature and salinity) or from a larger-scale ocean model (momentum). Two integrations were compared - one used a centred-difference advection scheme and viscous damping, while the other used a better representation of an advection scheme and a sub-gridscale eddy parameterization.

Tracer simulations showed (1) the importance of good representation of numerical advection, and (2) the role of eddy interacting with sea-floor topography (the neptune effect).
\end{abstract}

\section{INTRODUCTION}

For understanding the Arctic ice-ocean system it is necessary to develop coupled ice-ocean models that can reproduce climatological changes in appropriate ways. The occurrence of ice affects the forcing of ocean circulation. Likewise, heat and salt transport in the ocean helps determine the long-term thickness and extent of sea ice. Because most oceanic heat enters the Arctic from the Atlantic Ocean, correct representation of Atlantic water circulation is particularly important. Observed radionuclide distributions from European fuel reprocessing provide an opportunity to evaluate different circulation schemes for this water. We explore how the representation of sub-grid eddies and the improved numerical simulation of advection lead to a tracer distribution that is more consistent with that which is observed (Livingston and others, 1982a, b).

Soluble radionuclides, from the Sellafield nuclear-power station in northern England, are carried northwards from the Irish Sea, around the west coast of Scotland, and into the North Sea (Livingston and others, 1982a, b), mixing with additional components from La Hague (France). Then they are transported northwards in the Norwegian Coastal Current (Holm and others, 1983) before splitting off northern Norway. One branch flows eastwards into the Barents Sea, while the other becomes part of the West Spitsbergen Current, entering Nansen Basin through Fram Strait (Smith and others, 1990). A portion then returns southward in the East Greenland Current (Aarkrog and others, 1983; Livingston and others, 1985).

\section{MODEL DESCRIPTION}

A multi-level primitive-equation model (Bryan, 1969; Cox, 1989; Pacanowski, 1995) was coupled to a dynamic-thermodynamic sea-ice and snow model (Hibler, 1979; Parkinson and Washington, 1979), using a spherical coordinate system. The ocean was specified with three velocity components, potential temperatures and salinity, while the sea ice was specified with ice velocity, thickness and compactness. The sea-ice model supplied the heat, salt and momentum exchange for the ocean surface, whereas the ocean model supplied the current and heat-transfer data for the ice model. The atmospheric forcing (monthly climatological fields of wind stress, surface-air temperature, humidity, radiation and heat fluxes) came from datasets or bulk formulae (Trenberth and others, 1989; Schubert and others, 1993; Chapman and others, 1994).

The study covered the Arctic Ocean and northern parts of the Greenland and Norwegian Seas. Along the open boundaries with the Atlantic Ocean and Bering Sea, we used momentum boundary conditions derived from a larger-scale ocean model. Levitus' (1982) temperature and salinity data were applied for inflow with free conditions set for the outflow of tracers. To avoid the singularity effect at the Pole, we employed Eby and Holloway's (1994) grid rotation. The horizontal resolution of the model is $55 \mathrm{~km}$, with 29 levels in the vertical, covering a total depth of $4350 \mathrm{~m}$, and expanding in thickness from $10 \mathrm{~m}$ at the surface to $290 \mathrm{~m}$ in the deep ocean. The configuration of the basin is defined by the depth field from ETOPO5 (1986), with correction near the North Pole. 
The model includes parameterization of the interaction of the bottom topography and sub-gridscale eddies that act as a driving force (the "neptune" effect) in ocean circulation (Holloway, 1992; Alvarez and others, 1994). We present the results of two numerical experiments: a centered-difference advection (CDA) scheme with constant diffusion without neptune, and a flux-corrected transport (FCT) scheme (after Gerdes and others, 1991) with neptune parameterization. To limit the numerical dispersion by centered-difference advection, an explicit diffusion larger than can be attributed to physical mixing was added (Rood, 1987). For the centered-difference advection scheme, the horizontal and vertical diffusions were $10^{2}$ and $2 \times 10^{-5} \mathrm{~m}^{2} \mathrm{~s}^{-1}$, respectively.

From initial conditions of zero velocity, no ice, and annual mean Levitus (1982) temperature and salinity, integration proceeded under monthly-varying forcing until quasi-equilibrium was attained in the upper and intermediate depths. The acceleration method (Bryan, 1984) was used with this time-dependent forcing. Test cases using different acceleration ratios showed only a weak dependence on the acceleration factor. After quasi-equilibrium was attained, a constant tracer source was introduced into the Norwegian Coastal Current, as an idealized European source of reprocessing radionuclides. The models were then integrated for a further 15 years.

\section{RESULTS}

\section{Arctic Ocean}

Surface-water circulation in the Arctic Ocean is largely understood from studies of sea-ice drift. Prominent long-
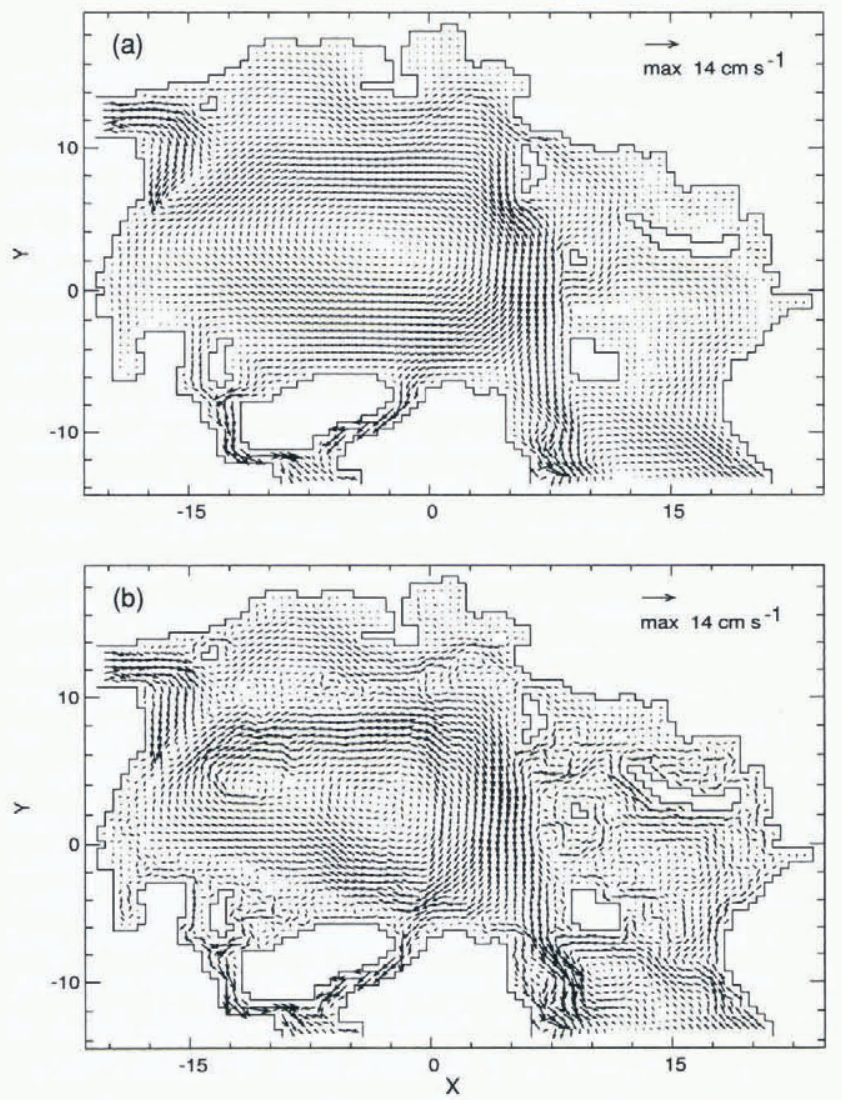

Fig.1. Velocities at $42.5 \mathrm{~m}$ for (a) CDA without neptune, and (b) FCT with neptune. term features of this are the anticyclonic Beaufort Gyre, which occupies most of the Canada Basin, and the Transpolar Drift that flows across the Pole towards Fram Strait. The coupled ice-ocean model qualitatively reproduces these features.

Sub-surface circulation $(42.5 \mathrm{~m})$ shows the Beaufort Gyre with only modest differences between CDA and FCT (Fig. 1). At this depth, water motion in the experiments does not produce the Transpolar Drift. However, ice motion (not shown) is nearly the same for both and is consistent with the observed Transpolar Drift.

The Norwegian Coastal Current (NCC), which follows the western and northern coast of Norway before flowing into the Barents Sea, splits into two main branches: one turns eastwards and continues as a coastal current, the other turns northwards before subdividing into smaller branches. Figure 1 shows differences in the Barents Sea circulation generated by the two experiments.

Two main currents exchange water through Fram Strait. The West Spitsbergen Current (WSC), an extension of the NCC, flows through Fram Strait, off the west coast of Spitsbergen, carrying warm, salty water into the Arctic Ocean. Its continuation is complex, as the current appears to split into two or more branches (Perkin and Lewis, 1984; Aagaard and others, 1987). For the CDA case with viscous damping (Fig. la), the WSC was not seen, but with FCT and neptune (Fig. lb) the near-surface WSC does appear.

The second main current is the East Greenland Current (EGC) that exits from the Arctic Ocean. Fram Strait appears to be a region of pronounced recirculation of Atlantic water, much of it joining the southward-moving EGC.

The differences between the two cases are clearly seen at intermediate depths (497.5 m, Fig. 2). With FCTand neptune
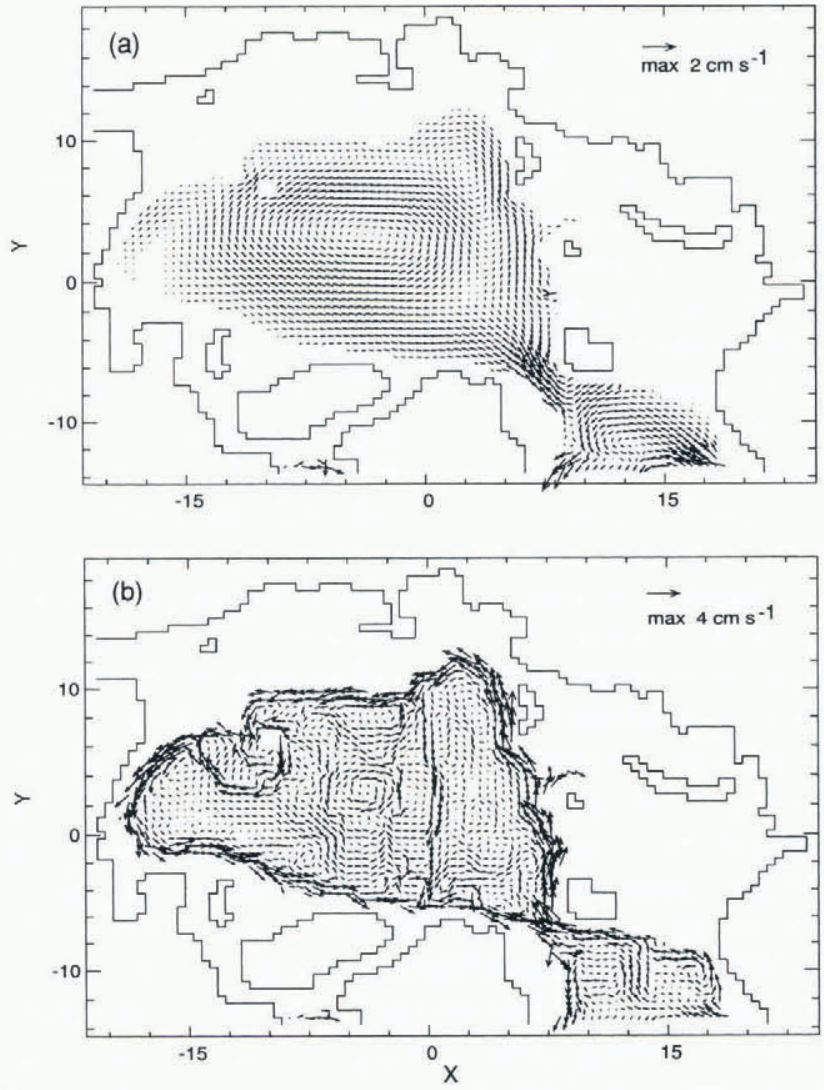

Fig. 2. Velocities at $497.5 \mathrm{~m}$ for (a) CDA without neptune, and (b) FCT with neptune. 

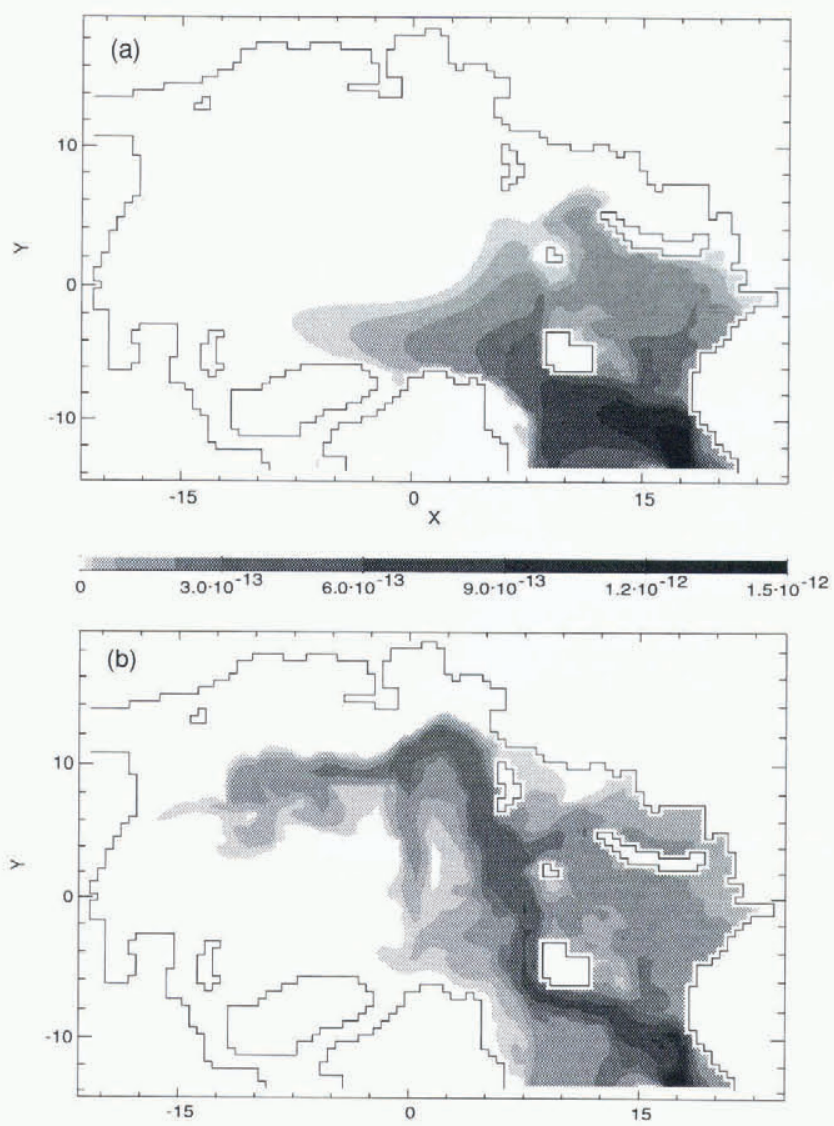

Fig. 3. Vertically integrated tracer burden. Units are burden per unit surface area, normalized by the source release for (a) CDA without neptune, and (b) FCT with neptune.
(Fig. 2b), the cyclonic circulation of Atlantic-derived water is dominated by several gyres steered by topographic features, such as the Gakkel, Lomonosov and Alpha-Mendeleev ridges. The FCT and neptune case also shows the exiting EGC at intermediate depths, a feature absent in the CDA viscous-damping case (Fig. 2a).

\section{Transport of contaminants}

To investigate potential radionuclide pathways in the Arctic Ocean, we included an idealized source, consisting of an assigned (constant) concentration on the open boundary from the NCC, to represent the European reprocessing contaminants as reported by Kershaw and Baxter (1995). Figure 3 shows the vertically integrated tracer burden after 15 years. The CDA without neptune (Fig. 3a) shows a diffuse contamination field because of a large explicit diffusion and unrealistic circulation.

The FCT case with neptune is more realistic (Fig. 3b). Some contaminants enter the Barents Sea via the NCC, while the rest flow northwards with the WSC. In Fram Strait, there is a partial recirculation southwards in the EGC (Figs 1, 2 and 3b) while the northward branch sinks and follows the shelf break in the Nansen Basin as a boundary current. This current is relatively strong, increasing with depth through the Atlantic layer into deeper water, and moving counter to the surface flow (Figs 1,2 and $3 \mathrm{~b}$ ). It takes contaminants along the Eurasian slope and returns along the Lomonosov Ridge (Fig. 3b). Contamination spreading to the Canada Basin is carried by a counter-clockwise flow along the continental margin opposite to the surface flow (Fig. 2).
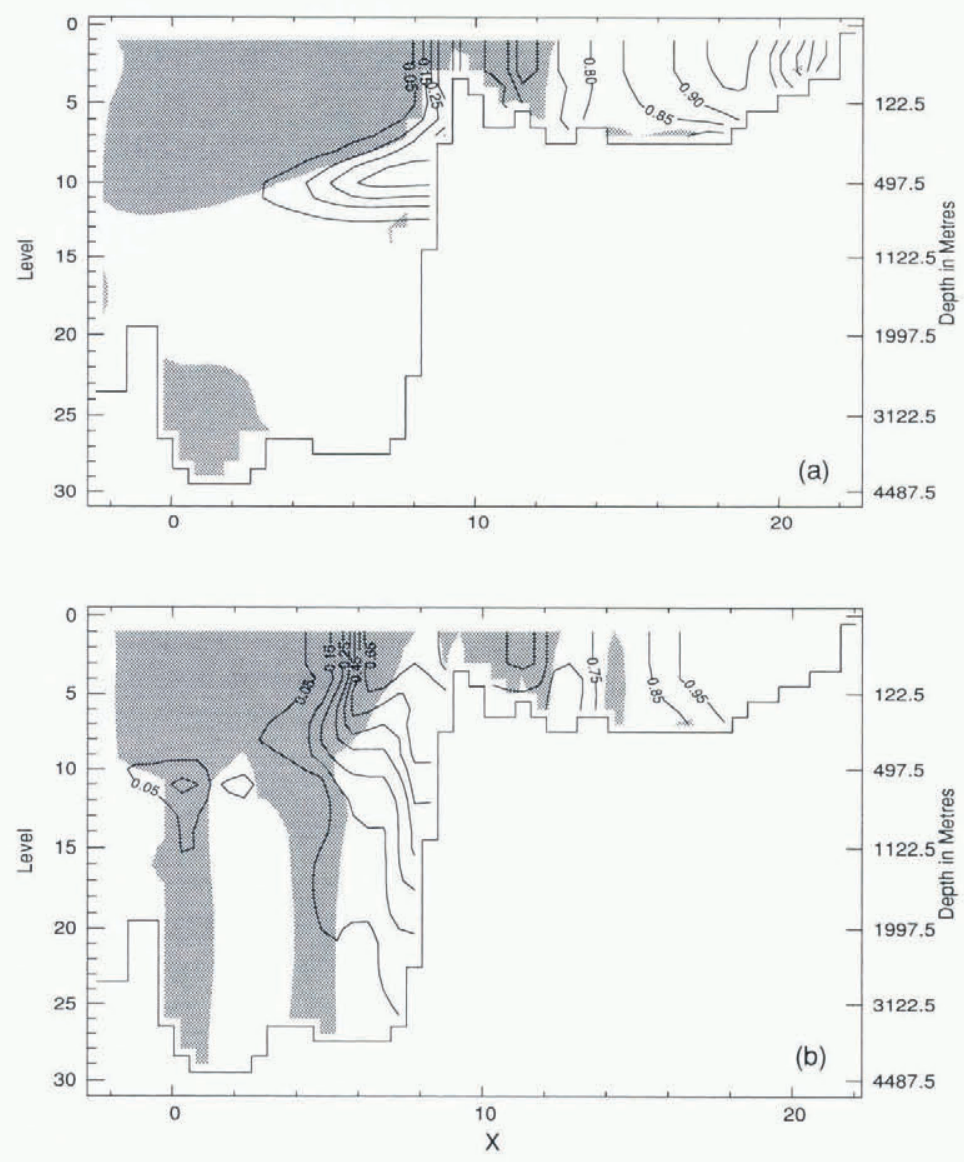

Fig. 4. Tracer concentration and velocity normal to the section $Y=0$ in Fig. 1. Shading indicates flow "out" of the page. Contours are tracer concentration relative to the source for (a) CDA without neptune, and (b) FCTwith neptune. 

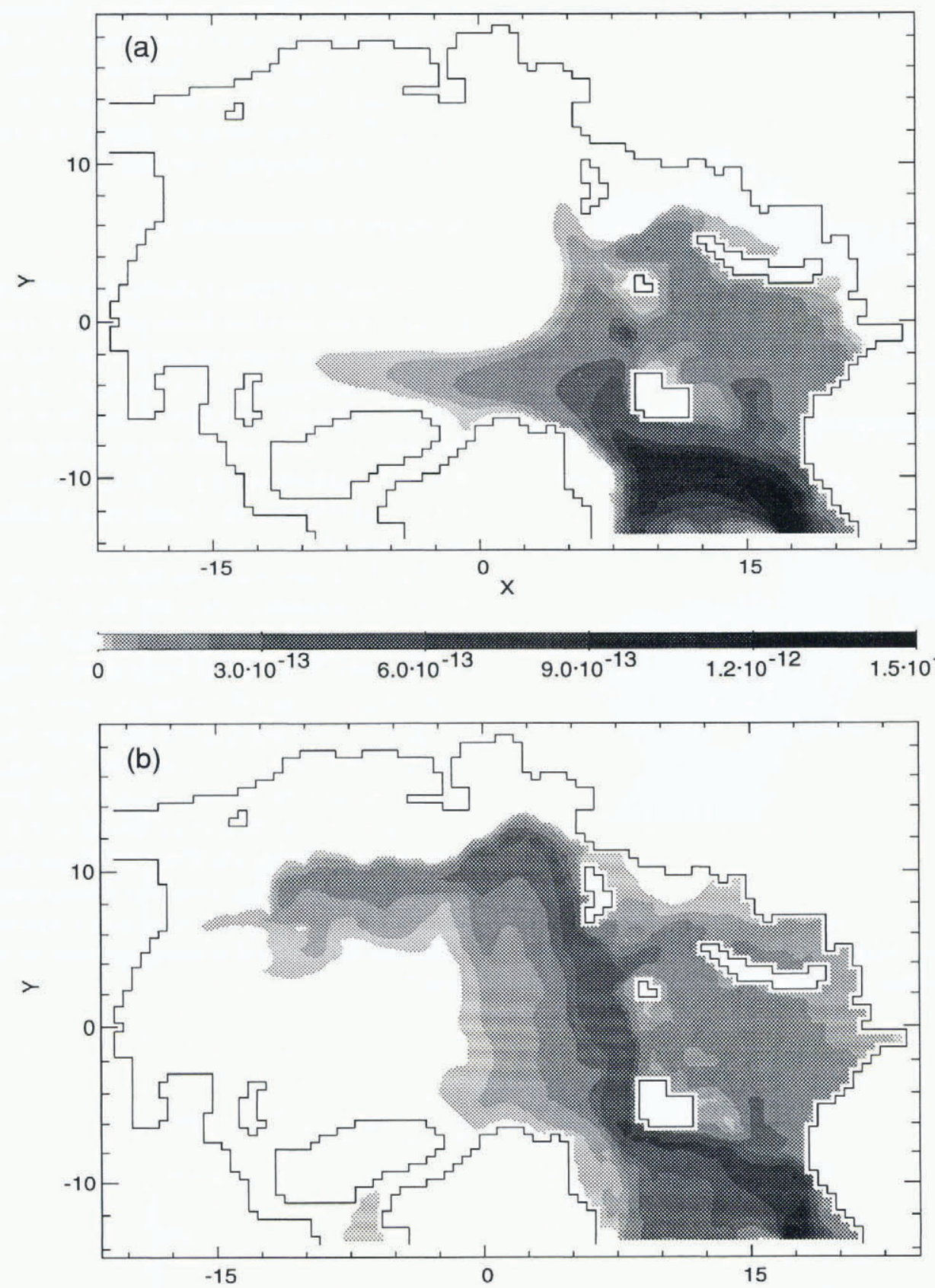

Fig. 5. Vertically integrated tracer burden for (a) FCT without neptune, and (b) CDA with neptune.

In the Barents Sea, contamination flows along the coast of Norway (Fig. 3). Most contaminants spread along the western coast of Novaya Zemlya (Fig. 2). Smaller branches of the NCG carry contamination to other parts of the Barents and Kara Seas. Modified Atlantic water in the Barents Sea exits along the eastern flank of the St Anna Trough, carrying contaminants into the Arctic Basin. Part of the WSC also turns into the Barents Sea along the western flank of this trough.

Figure 4 shows contamination concentration and velocity normal to a vertical sections along $\mathrm{Y}=0.0$ (through the North Pole). Shaded areas denote normal velocity "out" of the page (negative), while blank areas denote velocity "into" the page (positive). Near $\mathrm{X}=7.4$ contaminants are brought into the Arctic Ocean from Fram Strait by the intermediate-depth current. Much less contamination leaves the Arctic with the outflow at $\mathrm{X}=5.0$ (Fig. $4 \mathrm{~b}$ ) where velocities become negative. The model with FCT and neptune produces the returning flow along the Lomonosov Ridge at $\mathrm{X}=2.0$ (Fig. $4 \mathrm{~b}$ ).
The distribution of contamination from the CDA without neptune model is shown in Figure 4a. The distribution is dominated by the explicit diffusion, necessary to maintain numerical stability, that makes the contaminants spread in an unrealistic flow field (Kershaw and Baxter, 1995).

Because improvements have resulted from the use of FCT with neptune, the question arises as to how much each modification would contribute separately. Figure 5 has the same format as Figure 3, except that Figure 5a is based on FCT without neptune and Figure 5b uses CDA with neptune. Most of the overall improvement (Fig. 3b) results from including the neptune effect (on account of modified circulation patterns). The FCT is, nonetheless, helpful in retaining sharper property contrasts in the contaminant field and in the temperature and salinity fields.

Finally, a word of caution. Our comparisons were based upon the GFDL ocean model (Pacanowski, 1995) which is gridded on fixed z-levels. Model results are also dependent on the underlying architecture, which is sometimes poorly understood. We do not know how the apparent progress 
made here may carry over to other models such as the sigma-coordinate (Häkkinen and Mellor, 1992) or isopycnal-layer (Holland, 1994) models.

\section{SUMMARY}

A multi-level primitive-equation model, coupled to a dynamic-thermodynamic sea-ice model, was used to explore the distribution of radionuclides from idealized European reprocessing sources. The research focused on determining the possible effects of the parameterization for unresolved eddies, and an advection scheme on contamination distribution in the Arctic Ocean. The model with small mixing and improved physics (FCT with neptune) simulated a more realistic circulation and contamination distribution than the centered-difference advection scheme with constant diffusion (CDA without neptune).

\section{ACKNOWLEDGEMENTS}

This research has been supported in part by the Panel on Energy Research and Development (Canada) under project 6B2027 and by the Office of Naval Research under grant N00014-96-1-0518.

\section{REFERENGES}

Aagaard, K., A. Foldvik and S. R. Hillman. 1987. The West Spitsbergen Current: disposition and water mass transformation. 7. Geophys. Res., $92(4), 3778-3784$.

Aarkrog, A., H. Dahlgaard, H. Hansen and E. Holm. 1983. Radiocaesium from Sellafield effluents in Greenland waters. Nature, 304 (5921), 49-51.

Alvarez, A., J. Tintoré, G. Holloway, M. Eby and J. M. Beckers. 1994. Effect of topographic stress on the circulation in the western Mediterranean. J. Geophys. Res., $99(8), 16,053-16,064$.

Bryan, K. 1969. A numerical method for the study of the circulation of the world ocean. J. Comput. Phys., 14, 666-673.

Bryan, K. 1984. Accelerating the convergence to equilibrium of oceanclimate models. J. Phys. Oceanogr., 17 (7), 970985.

Chapman, W. L., W. J. Welch, K. P. Bowman, J. Sacks and J. E. Walsh. 1994. Arctic sea ice variability: model sensitivities and a multidecadal simulation. J. Geophys. Res., 99 (Cl), 919-935.
Cox, M. D. 1989. An idealized model of the world ocean. Part I. The globalscale water masses. J. Phys. Oceanogr., 19, 1730- 1752.

Eby, M. and G. Holloway: 1994. Grid transformation for incorporating the Arctic in a global ocean model. Climate Dyn., 10 (4-5), 241-247.

ETOPO5. 1986. Global 5' $\times$ 5'depth and elevation. Boulder, CO, U.S. Department of Commerce. (Code E/GC3.

Gerdes, R., C. Koberle andJ. Willebrand. 1991. The influence of numerical advection schemes on the results of ocean general circulation models. Climate Dyn., 5, 211-226.

Häkkinen, S. and G. L. Mellor. 1992. Modeling the seasonal variability of a coupled Arctic ice-ocean system. 7. Geophys. Res., 97 (C12), 20,285-20,304.

Hibler, W. D., III. 1979. A dynamic thermodynamic sea ice model. f. Phys. Oceanogr., 9 7), 815-846.

Holland, D. M. 1994. Numerical simulation of Arctic sea-ice and ocean circulation. Oceanography, 7, 27-28.

Holloway, G. 1992. Representing topographic stress for large-scale ocean models. J. Phys. Oceanogr., 22, $1033-1046$.

Holm, E., B. R. R. Persson, L. Hallstadius, A. Aarkrog and H. Dahlgaard. 1983. Radiocaesium and transuranium elements in the Greenland and Barents Seas. Oceanologica Acta, 6, 457-462.

Kershaw, P.J. and A. J. Baxter. 1995. The transfer of reprocessing wastes from north-west Europe to the Arctic. Deep-Sea Res., Ser. II, 42 6), 1413-1448.

Levitus, S. 1982. Climatological atlas of the world ocean. Rockville, MD, U.S. Department of Commerce. National Oceanic and Atmospheric Administration. (NOAA Professional Paper 13.

Livingston, H. D., V.T. Bowen and S. L. Kuperman. 1982a. Radionuclides from Windscale discharges, I: non-equilibrium tracer experiments in high latitude oceanography. 7. Marine Res., 40, 253-272.

Livingston, H. D., V.T. Bowen and S. L. Kuperman. 1982b. Radionuclides from Windscale discharges, II: their dispersion in Scottish and Norwegian coastal circulation. 7. Marine Res., 40, 1227-1258.

Livingston, H. D., J. H. Swift and H. G. Östlund. 1985. Artificial radionuclides tracer supply to the Denmark Strait overflow between 1972 and 1987. 7. Geophys. Res., 90 C4), $6971-6982$.

Pacanowski, R. C. 1995. Mom2 user's guide and reference mamual. Version 1 . Princeton, NJ, NOAA. GFDL Ocean Group. (Technical Report 3. )

Parkinson, C. L. and W. M. Washington. 1979. A large-scale numerical model of sea ice. 7. Geophys. Res., $84(\mathrm{Cl}), 311-337$.

Perkin, R. B. and E. L. Lewis. 1984. Mixing in the West Spitsbergen current. J. Phys. Oceanogr., 14, 1315-1325.

Rood, R. B. 1987. Numerical advection algorithm and their role in atmospheric transport and chemistry models. Rev. Geophys., 25, 71-100.

Schubert, S. D., R. B. Rood and J. Pfaendtner. 1993. An assimilated dataset for earth science applications. Bull. Am. Meteorol. Soc., 74 12, 2331-2342.

Smith, J. N., K. M. Ellis and E. P. Jones. 1990. Caesium 137 transport into the Arctic Ocean through Fram Strait. 7. Geophys. Res., 95 (2), 1693-1701.

Trenberth, K. E., J. G. Olson and W. G. Large. 1989. A global ocean wind stress climatology based on ECMWF analyses. Boulder, CO, National Center for Atmospheric Research. (NCAR Technical Note TN-338+STR.) 